\title{
Reconsideration and upgrading of sampling and analysis methods for avoiding measurement-related design and operation failures in wastewater treatment
}

\author{
V Bakos ${ }^{1 *}$, A Deák² and A Jobbágy ${ }^{1}$ \\ 'Dept. Applied Biotechnology and Food Science, Budapest University of Technology and Economics, H-1111 Budapest, Szent Gellért tér 4, Hungary \\ ${ }^{2}$ Dept. Sewage Operations, Budapest Central Wastewater Treatment Plant, Budapest Waterworks Pte. Ltd., H-1211 Budapest, Nagy Duna sor 2, Hungary
}

\begin{abstract}
Success of design and high operational efficiency may basically stand or fall on the quality of measured (or estimated) input data. Even small mistakes committed in the initial steps of sampling and analysis may become large once scaled up in the design process or during full-scale operation. The paper provides several experiment-based practical recommendations and easily implemented, powerful methods for appropriate sampling and analysis practice in wastewater treatment. Representative wastewater characterization is crucial for satisfactory design and cost-effective operation. The paper highlights hidden problems and challenges of sampling and analysis in activated sludge wastewater treatment which may strongly affect the quality of input data, and thus basically determine the modelling outputs. Full-scale results proved that wastewater quality may change significantly in the sampling tubing and vessels; during the sampling process even nitrification can happen. Regarding sludge settling measurements, effects of dilution, temperature, floc structure, nitrate and dissolved oxygen concentrations as well as current biochemical condition of the sludge sample have been studied and important recommendations provided. A combined comparative method including SVI and DSVI measurements has been elaborated for indication and early warning alert of undesired floc structure transformations. Influent $\mathrm{BOD}_{5}$ concentration is a key factor for describing biodegradability and denitrification capacity of wastewater to be treated. Results of the two most commonly used BOD testing methods were compared for preclarified wastewater. An electrochemical measurement technique provided significantly lower $\mathrm{BOD}_{5}$ concentrations compared to manometric analysis results with a difference of $23 \%$ and $15 \%$ on average for unfiltered and filtered samples, respectively. Effects of BOD-based fractionation deviations on predictable denitrification efficiency were studied at different inlet $\mathrm{C} / \mathrm{N}$ ratios by simulating existing full-scale wastewater treatment plants resulting in remarkable differences in effluent nitrate concentrations. Based on the results, application of the manometric BOD measurement method proved to be preferable.
\end{abstract}

Keywords: wastewater sampling, measurement errors, data accuracy, biochemical oxygen demand, sludge volume index, activated sludge model

\section{INTRODUCTION}

The quality of the data acquired for design, optimization and operation of wastewater treatment depends strongly on the sampling and measurement methods applied. While an extremely wide range of sources of failure may be considered, appropriate analysis and sensor calibration (Rieger et al., 2004; 2006), as well as having a good concept of data acquisition and critical evaluation (Rieger et al., 2010), may help to provide adequate simulation results and accurate estimations of treatment efficiency (Hauduc et al., 2013). Although instrumentation, control and automation applications for wastewater treatment systems are continuously developing, there are still 'blank spots' in this field, principally in sewer control (Olsson et al., 2014). Advanced sampling, measurement and laboratory techniques ensure appropriate technical support to choose technologies with special regard to local conditions, instead of using generalized rules of thumb as predominant design guidelines (Tardy et al., 2012). Despite its importance, little care may sometimes be taken on the origin of initial data, background of sampling and analysis methodology; moreover, this information may not be available at all. This shortage, coupled with sampling and/or measurement failures, can lead to high

*Corresponding author, email: vbakos@mail.bme.hu

Received 4 April 2018; accepted in revised form 14 June 2019 uncertainties in wastewater quality, and may be the bottleneck limiting the success of technological concepts proposed.

The current study illustrates effects that may largely influence the accuracy of measured data used for design and operation. Sludge volume index (SVI) is a key design parameter for secondary clarifier dimensioning and for appropriate operation. Numerous important models and methods have been elaborated and widely studied for the determination of activated sludge settleability (Ekama et al., 1984 and 1997; Jenkins et al., 2004; Wanner and Jobbágy, 2014). However, measurements for sludge settling may still involve possible major problems which have not been thoroughly discussed to date, and which may result in inaccurate data and failures in design and operation. Methods that might be used at different wastewater treatment plants (WWTPs) are still diverse and not transparent to enable comparison from site to site.

Another basic parameter, biochemical oxygen demand (BOD), has a key role in bioreactor and aeration dimensioning; moreover, it is an important background parameter influencing the biodegradability-based chemical oxygen demand (COD) fractionation (Ekama et al., 1986; Roeleveld and Loosdrecht, 2002; Drewnowski and Makinia, 2014) considerably in ASM (activated sludge model) based simulations. Although several different standard methods are widely used in international laboratory practice, the detailed analytical background of the data is generally unknown during evaluation for simulation studies. 
This paper highlights a number of typical sampling and monitoring failures and uncertainties that can lead to inadequate wastewater characterization, and consequently to poor system design and operation. The purpose of this paper is to show the importance of representative and appropriate sampling and analysis by presenting the high operational impacts of measurement and sampling failures. Moreover, the paper aims to provide useful experiment-based recommendations towards upgrading sampling as well as SVI and BOD measurement methods for avoiding design and operation failures and supporting cost-effective plant operation.

\section{MATERIALS AND METHODS}

\section{Analytical methods}

COD (chemical oxygen demand), TSS (total suspended solids), VSS (volatile suspended solids), MLSS (mixed liquor suspended solids), ammonium, nitrate, nitrite and DO (dissolved oxygen) concentrations were measured according to standard analytical methods (APHA, 1999). For the measurement of filtered, flocculated COD the flocculation method of Mamais was used (Mamais et al., 1993). DO concentration was measured by portable WTW Multi 3420 FDO Check meter (WTW GmbH, Weilheim, Germany).

\section{SVI and DSVI measurements}

For both on-site and laboratory settling measurements activated sludge samples were taken between the $30^{\text {th }}$ and $60^{\text {th }}$ minutes of aeration from intermittently aerated bioreactors of 4 Hungarian activated sludge WWTPs, namely, Budapest Central WWTP (BCWWTP, max. hydraulic capacity: $350000 \mathrm{~m}^{3} \cdot \mathrm{d}^{-1}$, the largest facility in Hungary), Biatorbágy WWTP (BIAWWTP, max. hydraulic capacity: $2000 \mathrm{~m}^{3} \cdot \mathrm{d}^{-1}$ ), North Budapest WWTP (NPWWTP, ave. hydraulic load: $150000 \mathrm{~m}^{3} \cdot \mathrm{d}^{-1}$ ) and Kecskemét WWTP (KWWTP, ave. hydraulic load: $22000 \mathrm{~m}^{3} \cdot \mathrm{d}^{-1}$ ) in the period between January and June, 2015. BCWWTP, BIAWWTP and NPWWTP basically have a pre-denitrifying MLE (Modified Ludzack-Ettinger) bioreactor arrangement, applying intermittent aeration in the aerobic zone for reducing effluent nitrate content. KWWTP has only intermittently aerated carousel-type bioreactors without a preceding non-aerated zone. SVI and DSVI (diluted sludge volume index) were determined according to standard methods (HSI, 2006, No. MSZ EN 14702-1,2:2006; Jenkins et al., 2004) where treated effluent was used for dilution. During the on-site measurements, $10 \mathrm{~L}$ of additional mixed liquor sample were taken for further laboratory investigations. In the laboratory the sample was homogenized, and divided into 4 different lab-scale reactors. Two of these were run without aeration with smooth mixing (i.e. non-pre-aerated samples), and the other two were intensively aerated for $2 \mathrm{~h}$ (i.e. pre-aerated samples). The experiments were carried out at 20 and $25^{\circ} \mathrm{C}$. Before the settling measurements nitrate concentrations of the mixed liquors were determined. Then appropriate amounts of $\mathrm{KNO}_{3}$ solution were added to each of the systems in order to set nitrate concentration at a lower $\left(10 \mathrm{mg} \cdot \mathrm{L}^{-1} \mathrm{NO}_{3} \mathrm{~N}\right)$ or a higher $\left(25 \mathrm{mg} \cdot \mathrm{L}^{-1}\right.$ $\mathrm{NO}_{3} \mathrm{~N}$ ) value. One non-aerated and one aerated system was applied for each nitrate setting. After $10 \mathrm{~min}$ both SVI and DSVI measurements were carried out. Native activated sludge samples were investigated by Olympus CX41 microscope (magn. 200x, phase contrast).

\section{BOD measurements, statistical analysis and mathematical modelling}

For the comparative study on $\mathrm{BOD}_{5}$ measuring protocols, both the electrochemical method (HSI, 2000, No. MSZ EN 1899-1,2:2000; APHA, 1999, No. 5210B., membrane electrode) and manometric technique (HSI, 2004, No. MSZ E 214209:2004; APHA, 1999, No. 5210D.) were applied. For manometric measurements WTW OxiTop Control System was used (WTW $\mathrm{GmbH}$, Weilheim, Germany). The measurements were carried out both for unfiltered and filtered raw inlet and preclarified wastewater ( 5 times, applying 5 parallels) samples taken at BIAWWTP and BCWWTP, respectively. For wastewater characterization ultimate BOD was determined from raw inlet and preclarified wastewater samples and biodegradable COD was calculated according to related guidelines (STOWA, 1996; Roeleveld and Loosdrecht, 2002) and standards (APHA, 1999, No. 5210C.). Raw wastewater samples were taken from the raw inlet of BIAWWTP after the screens, and preclarified wastewater represents the effluent of the Sedipac 3D type primary clarifiers (i.e. combined grit and grease removal and primary settling) of BCWWTP. Statistical analysis of measured BOD results was performed by Dell Statistica (Dell Inc., 2015, version 12, software. dell.com). Since excess biological phosphorus removal was beyond the scope of the study, simulations were carried out using the ASM1 (Activated Sludge Model No. 1, Henze et al., 1987) based WEST software (http://www.mikepoweredbydhi.com/). Calculations were carried out for BCWWTP and BIAWWTP, both having pre-denitrification and intermittently aerated carousel-type bioreactors located between the non-aerated zone and the secondary clarifiers, according to the technological layout of the investigated plants presented in Figs 1 and 2.

Table 1 lists a possible characteristic spectrum of raw influent wastewater qualities of BIAWWTP as well as a characteristic preclarified wastewater quality of BCWWTP applied for mathematical simulation studies. The presented influent

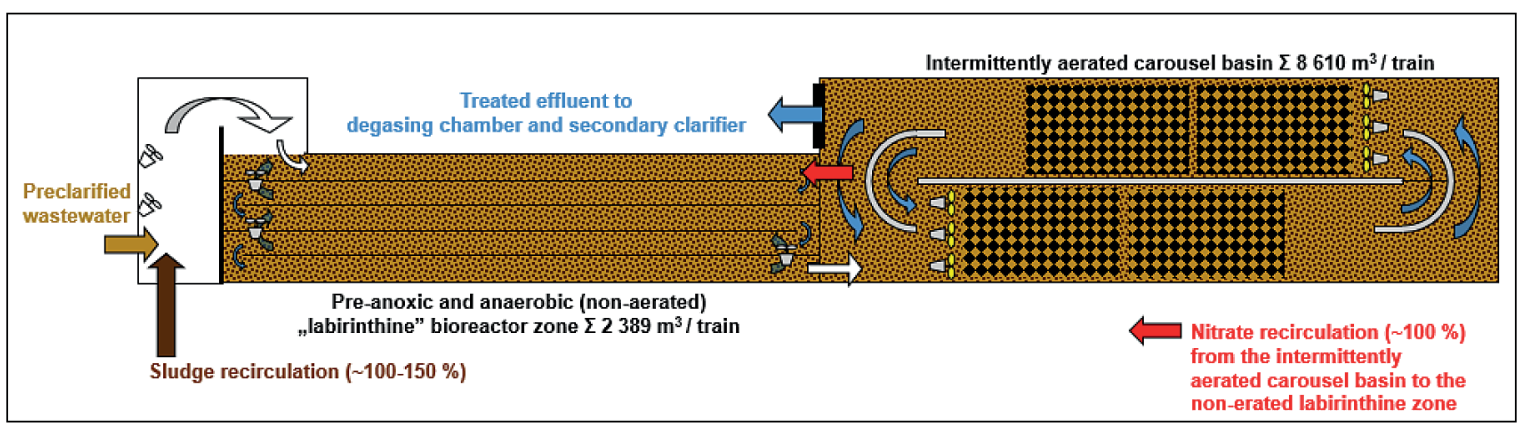

Figure 1. Technological layout of one biological train of BCWWTP; in the period of the investigations 14 out of the 18 biological trains were in operation 
wastewater qualities were determined on the basis of on-site measurements. Effluent concentrations were also measured for model fitting and validation. A BOD-based COD fractionation model was developed according to the guidelines of the STOWA simulation protocol (STOWA, 1996; Roeleveld and Van Loosdrecht, 2002). The fractionation model was fitted by supplementary analysis for flocculated and filtered COD concentration in order to confirm its applicability. According to the characteristic bioreactor temperatures measured in June 2015 , steady-state simulations were run at $20^{\circ} \mathrm{C}$ after appropriate fitting and validation of the model. The real influent quality and operational settings of BCWWTP (for



Figure 2. Technological layout of the biological step of BIAWWTP
1 June 2015) and BIAWWTP (for 5 different operational days in June, 2015) were applied for simulations and the calculated effluent concentrations of $\mathrm{N}$ forms were compared to the measured values of the treated effluent. The measured inlet flow rate was $225900 \mathrm{~m}^{3} \mathrm{~d}^{-1}$ at BCWWTP and varied between 1722 and $2681 \mathrm{~m}^{3} \cdot \mathrm{d}^{-1}$ at BIAWWTP on the sampling days. In the period of the investigations, intermittently aerated carousel basins operated with cycle settings of alternating 2-h long aerated and 1-h long non-aerated periods, at MLSS concentration of approx. $2.8 \mathrm{~kg} \cdot \mathrm{m}^{-3}$ at BCWWTP, and settings of 50-min long aerated and 10-min long non-aerated periods at approx. $4.2 \mathrm{~kg} \cdot \mathrm{m}^{-3}$ MLSS at BIAWWTP.

\section{RESULTS AND DISCUSSION}

\section{Failures and latent challenges in sampling and determination of inlet wastewater quality}

As illustrated in Fig. 3 autosamplers and sampling vessels may operate as bioreactors due to non-desired attached growth even leading to nitrification while resulting in false analytical data. At BCWWTP the significant change of the inlet wastewater quality was detected after the translocation of the inlet sampling point by approx. $10 \mathrm{~m}$ along the inlet wastewater receiving channel. Since only the autosampler inlet tubing was transferred without

Table 1. The influent wastewater quality and effluent dissolved COD concentrations at BCWWTP and BIAWWTP applied for mathematical simulations

\begin{tabular}{|c|c|c|c|c|c|c|c|}
\hline \multirow[t]{2}{*}{ Parameter } & & \multirow{2}{*}{$\begin{array}{c}\text { BCWWTP } \\
\text { Pre-clarified } \\
1 \text { June } 2015\end{array}$} & \multicolumn{5}{|c|}{$\begin{array}{c}\text { BIAWWTP } \\
\text { raw inlet (after screens) }\end{array}$} \\
\hline & & & 3 June 2015 & 10 June 2015 & 19 June 2015 & 24 June 2015 & 30 June 2015 \\
\hline Total COD & $\mathrm{g} \cdot \mathrm{m}^{-3}$ & 513 & 782 & 737 & 1057 & 614 & 883 \\
\hline Dissolved COD & $\mathrm{g} \cdot \mathrm{m}^{-3}$ & 223 & 292 & 234 & 365 & 150 & 305 \\
\hline Total $\mathrm{BOD}_{5} *$ & $\mathrm{~g} \cdot \mathrm{m}^{-3}$ & 240 & 434 & 353 & 626 & 287 & 499 \\
\hline TSS & $\mathrm{g} \cdot \mathrm{m}^{-3}$ & 200 & 371 & 547 & 685 & 530 & 564 \\
\hline $\mathrm{NH}_{4} \mathrm{~N}$ & $\mathrm{~g} \cdot \mathrm{m}^{-3}$ & 45.4 & 78.9 & 95.3 & 69.6 & 42.2 & 66.5 \\
\hline TKN & $\mathrm{g} \cdot \mathrm{m}^{-3}$ & 62.7 & 87.4 & 108.5 & 84.3 & 54.9 & 75.4 \\
\hline Effluent dissolved COD & $\mathrm{g} \cdot \mathrm{m}^{-3}$ & 27 & 25 & 30 & 42 & 31 & 39 \\
\hline $\mathrm{BOD}_{5} / \mathrm{NH}_{4} \mathrm{~N}$ & - & 5.3 & 5.5 & 3.7 & 9.0 & 6.8 & 7.5 \\
\hline
\end{tabular}

${ }^{*} \mathrm{BOD} \mathrm{D}_{5}$ concentrations are given according to manometric $\mathrm{BOD}$ measurement method

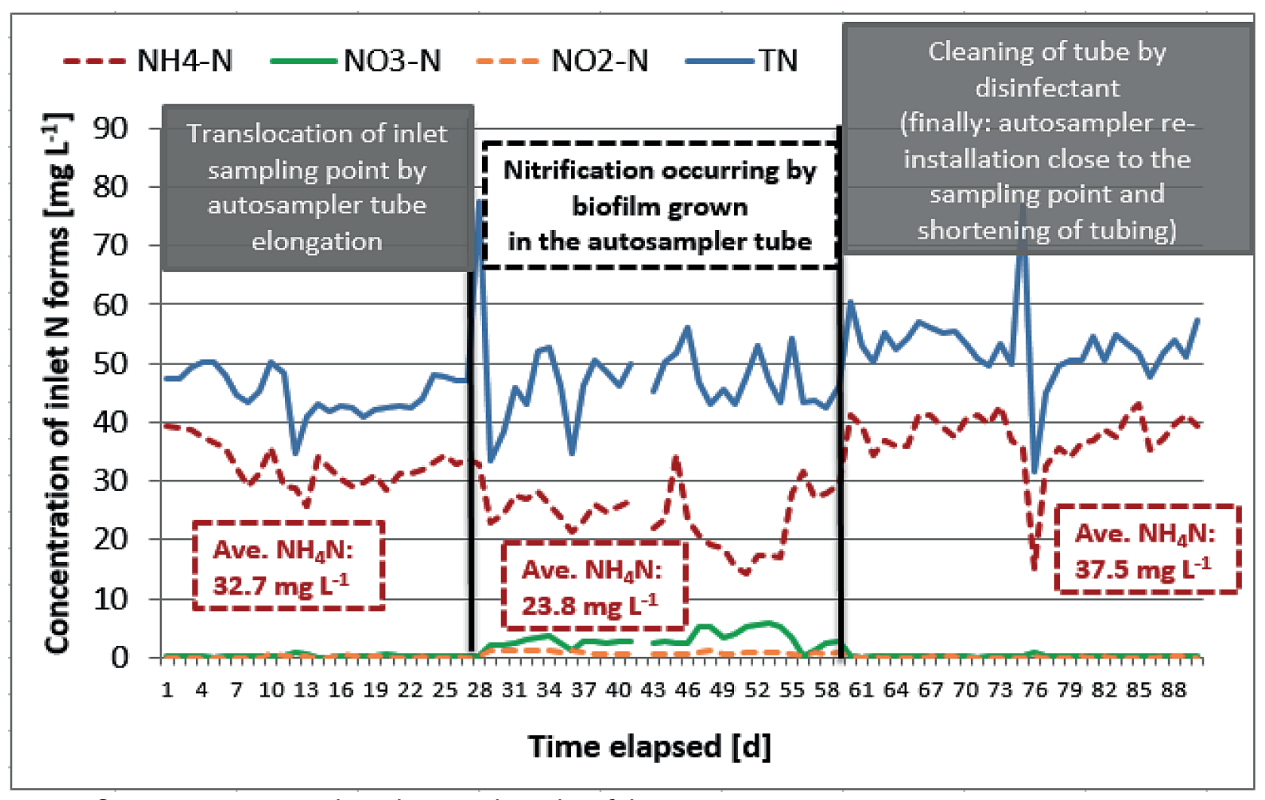

Figure 3. Spontaneous nitrification in autosampler tubing and results of the corrective actions 
the translocation of the sampling device, partial sedimentation of the sample and inner biofilm formation occurred in the long and curvy hose. This led to the increase of inlet total COD and TSS concentrations measured as well as to relatively intensive nitrification which was detectable both by the remarkably decreased inlet ammonium concentration and by the increasing inlet nitrate level up to approx. $5 \mathrm{mg} \cdot \mathrm{L}^{-1} \mathrm{NO}_{3} \mathrm{~N}$, and additionally, nitrite also appeared in the influent. The problem was quickly detected and other possible causes were carefully investigated and excluded (e.g. by comparison of grab samples quality at both sampling points). The sampling nuisance was eliminated by changing and cleaning the inlet tube using disinfectant and the autosampler was brought directly next to the new sampling point which allowed the shortening of the sampling tube as well.

\section{Recommendations and methods for appropriate autosampler operation and maintenance practice as well as for detection of measurement failures}

Cleaning of the inner spare parts and hose of autosamplers is recommended to be a regular preventive maintenance process. Operators are advised to position the autosampler close to the sampling point for minimizing the hose length and to fix the sampling tube properly without saggings and loops where suspended solids can settle down and danger of biofilm formation can be increased. For quick detection of deficient data and measurement failures, regular follow-up of historical data and application of cross-checking calculations (e.g. calculating $\mathrm{BOD}_{5} /$ $\mathrm{COD}$ ratio, influent $\mathrm{N}$ forms, etc.) are highly recommended. In case of the introduction of new sampling and/or measurement techniques or relevant modifications in the former practice, the careful tracking of the new results, their comparison with earlier data or even more their simultaneous check and comparison with the results of the formerly applied (reference) method of long standing are strongly recommended preventive actions.

\section{SVI and DSVI measurements and effects of several biochemical influencing factors}

\section{On-site measurement of SVI and DSVI at four full-scale WWTPs}

In the common practice for testing sludge settleability both SVI and DSVI methods have been widely applied. When the settled sludge volume exceeds $200-250 \mathrm{~cm}^{3} \cdot \mathrm{L}^{-1}$, depending on the protocol (e.g. Ekama et al., 1997; ATV, 2000; Jenkins et al., 2004; Wanner and Jobbágy, 2014), dilution may be recommended. However, typically from spring to fall at the relatively low applicable MLSS concentrations this technique may result in excessively diluted MLSS content close to (or lower than) $1 \mathrm{~kg} \cdot \mathrm{m}^{-3}$ in the test-cylinder, which may just be marginally appropriate for sludge flocculation. Figure 4 illustrates selected characteristic SVI and DSVI measurement results of a 6-month long investigation period (January-June, 2015). Samples were taken several times at the four investigated WWTPs operated at diverse MLSS concentrations and the results of samples with different filamentous abundance are presented.

During investigation of the factors possibly influencing SVI and DSVI it has been found that increasing filament abundance not only increases these values, but the difference between them as well. Moreover, MLSS had no remarkable effect on this in the investigated biomass concentration range of $2.8-6.0 \mathrm{~kg} \cdot \mathrm{m}^{-3}$ MLSS. As illustrated in Fig. 4, the gap between SVI and DSVI proved to be higher with higher filament abundance. This observation is in accordance with the experience of Lee et al. (1983) regarding the relationship found between TEFL (total extended length of filaments) values and sludge volume indices.

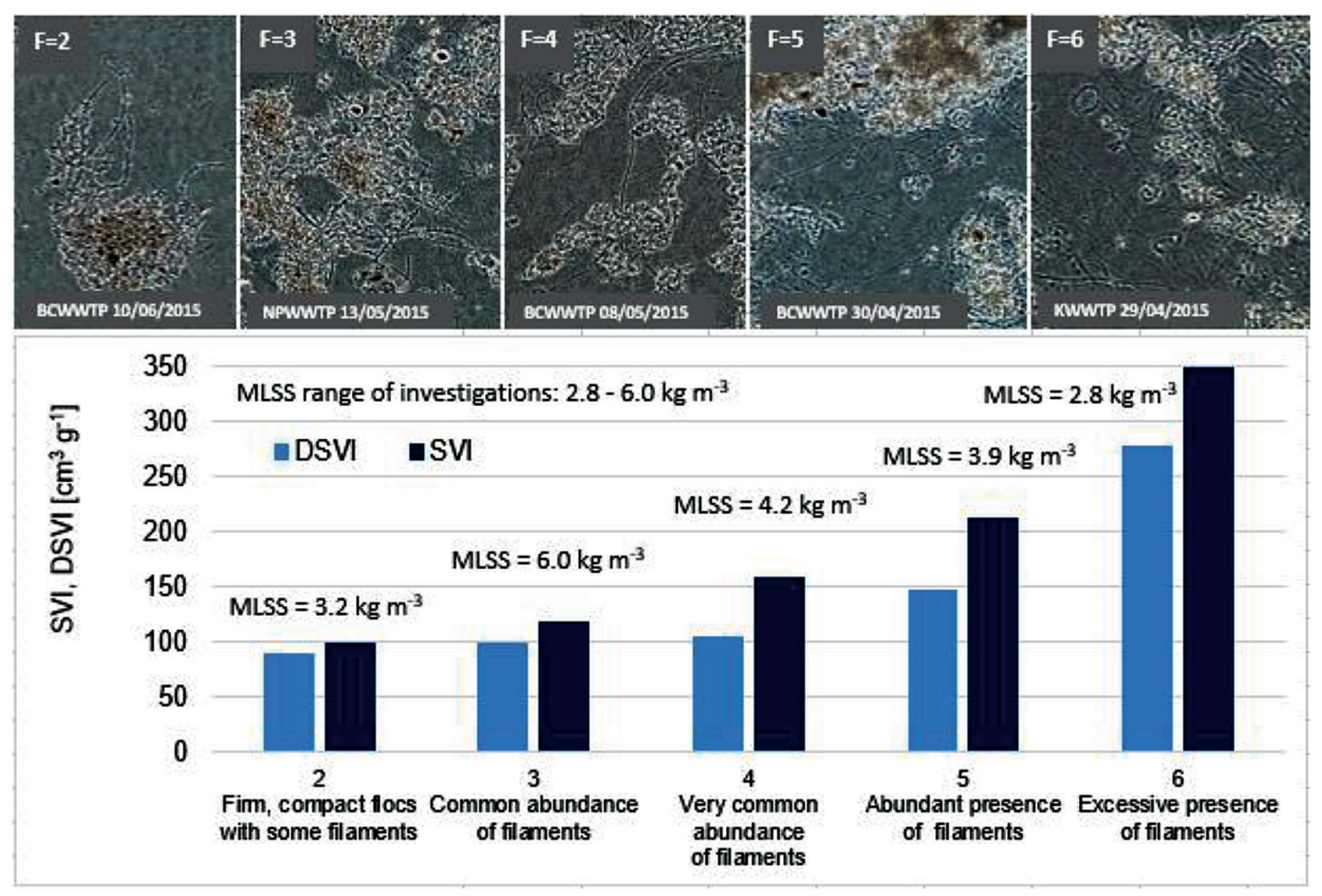

Figure 4. Correlation of filament abundance with the difference between SVI and DSVI values measured. Filament abundance $\mathrm{F}$ was determined by the scoring method of Jenkins: 0-none; 1-few; 2-some; 3-common; 4-very common; 5-abundant; 6-excessive (Jenkins et al., 2004). 


\section{Combined comparative method for following sludge settleability}

At BCWWTP the settleability of activated sludge characteristically deteriorates in the winter period (see Fig. $5 \mathrm{a}$ and $\mathrm{b}$ ), in accordance with the common experience of fullscale plant operators. Both decreasing bioreactor temperature and decreasing F/M ratio (due to higher MLSS concentration maintained in winter for increasing sludge age) may be cited to explain increasing SVI values. The typical MLSS concentration varies between 2.0 and $2.5 \mathrm{~kg} \cdot \mathrm{m}^{-3}$ for the summer and is in the range of $3.0-4.0 \mathrm{~kg} \cdot \mathrm{m}^{-3}$ for the winter season. In the most affected periods of floc structure transformations (i.e. at remarkable increase or decrease of filament abundance) both SVI and DSVI measurement methods were applied simultaneously. When the floc structure was close to ideal (i.e. firm flocs with the presence of some filaments), the SVI and DSVI values were practically equal in the investigated MLSS range. However, the higher the filamentous abundance was, the larger the difference that could be detected between the SVI and DSVI data measured.

Full-scale experiences at BCWWTP showed that SVI may be more sensitive for detecting changes in filament abundance, whereas in winter, when relatively high MLSS concentration can be coupled with increased filament abundance, DSVI may better indicate the sludge level variations in secondary clarifiers. In the critical floc structure changing periods (see Fig. 5), the combined comparative measurement of both SVI and DSVI could unambiguously, accurately and even earlier indicate the encouraged (or suppressed) growth of filaments, relative to microscopic observations which have limited quantifying capacity.

\section{Laboratory experiments}

For further laboratory experiments activated sludge samples were taken from the same WWTPs that were being investigated. Each of them contains an intermittently aerated bioreactor connected directly to the secondary clarifier. Figure 6 shows that the biochemical switch of the biomass (i.e. switching from anoxic to aerobic conditions by aeration) is crucial regarding the results of settling measurements. The impact of the available electron acceptor (oxygen or nitrate) proved to be more remarkable at higher abundance of filaments even at moderate temperature $\left(20^{\circ} \mathrm{C}\right)$. At higher temperature $\left(25^{\circ} \mathrm{C}\right)$ and higher nitrate concentration $\left(25 \mathrm{mg} \cdot \mathrm{L}^{-1} \mathrm{NO}_{3} \mathrm{~N}\right)$ the risk of sludge flotation increased considerably, particularly for non-pre-aerated samples. In the case of for $30 \mathrm{~min}$ pre-aerated samples, the settled sludge had a compact structure in the cylinder with a sharp horizontal upper surface and rising sludge was not detectable, whereas in the non-pre-aerated settled sludge samples a porous, flowing structure could be observed, and the upper surface was rough and irregular. While pre-aerated sludge followed the physical rules of settling, at $25^{\circ} \mathrm{C}$ settling of non-pre-aerated systems could rather be considered as a kind of complex bio-hydraulic process due to denitrification start-up (i.e. additional suspension flows and circulations). Independently of the biochemical switch of the samples (i.e. incubation carried out with or without aeration), at the start of settling measurement all of the cylinders contained considerable concentrations of dissolved oxygen (DO) due to intensive air input through filling up with sample as well as dilution with DO-rich (5-6 mg.L $\left.\mathrm{L}^{-1} \mathrm{DO}\right)$ treated effluent used for measuring DSVI. The DO level was still relatively high at the

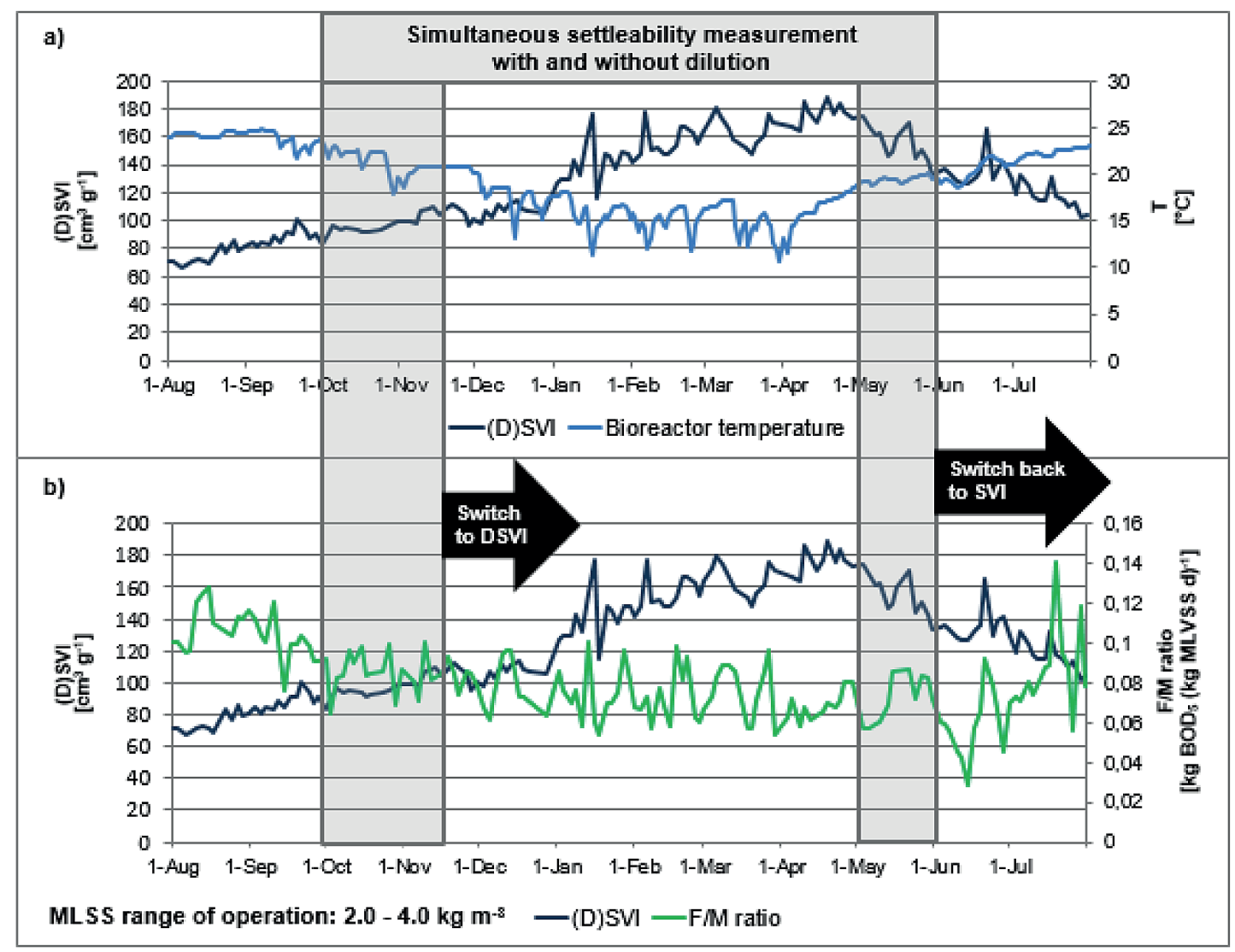

Figure 5. Sludge settleability results at BCWWTP between 01.08.2012 and 31.07.2013 coupled with a) the bioreactor temperature and b) the calculated F/M ratio 




Figure 6. Results of SVI and DSVI measurements after aerobic (pre-aerated) or anoxic (non-pre-aerated) incubation of samples at different temperatures $\left(20^{\circ} \mathrm{C}\right.$ and $25^{\circ} \mathrm{C}$ ) and nitrate levels (10 and $25 \mathrm{mg} \cdot \mathrm{L}^{-1} \mathrm{NO}_{3} \mathrm{~N}$ ); filament abundance was determined by the scoring method of Jenkins: 0-none; 1-few; 2-some; 3-common; 4-very common; 5-abundant; 6-excessive (Jenkins et al., 2004)

end of the measurement (after $30 \mathrm{~min}$ ); even for non-pre-aerated sludge it could reach $2-3 \mathrm{mg} \cdot \mathrm{L}^{-1} \mathrm{DO}$ at $20^{\circ} \mathrm{C}$. It is well known that DO has strong inhibitory effect on denitrification (Jobbágy et al. 2000; Plósz et al., 2003); therefore intensive agitation of mixed liquor prior to the measurement may prevent sludge flotation during the $30 \mathrm{~min}$ of the settling test under low $\mathrm{S}$ (i.e. low substrate concentration - shortage of readily biodegradable COD) conditions. However, it may not be enough for appropriate anoxicaerobic switch and to avoid slight swelling of the sludge in the cylinder in case of samples prepared without appropriate aeration. At $25^{\circ} \mathrm{C}$, in the case of non-pre-aerated samples, DO concentration could fall to zero during the measurement and this was definitely coupled with detectable nitrate elimination and total flotation of the sludge.

Recommendations and methods for appropriate activated sludge sampling and sludge settleability measurement practice

In the case of intermittently aerated bioreactors it is recommended to take activated sludge samples in the aerated phase of operation (after at least $30 \mathrm{~min}$ aeration if possible), in order to avoid settling nuisances caused by denitrification in the measuring cylinder. (Similarly, in full-scale it is recommended to insert a small intensively aerated reaeration tank between the intermittently aerated basin and the secondary clarifier.) For ensuring data accuracy and comparability, it is recommended that samples are always taken in the same way, according to a fixed protocol. At WWTPs operating with several parallel biological trains and applying intermittent aeration, in particular, the use of advanced automatic sludge volume and MLSS meters with a sampling pattern adjusted to the aeration cycles can be a good and powerful solution (with regular cleaning and maintenance required). At WWTPs where regular careful microscopic observations and floc structure follow-up cannot be carried out it is suggested to apply the simultaneous and comparative measurement of SVI and DSVI, at least in the crucial floc structure changing periods, for early indication of filament abundance changes. SVI indicates at an earlier time the increase of filament abundance; however, DSVI may better represent the conditions (e.g. sludge blanket level) of the full-scale secondary clarifier. It has been proven that filament abundance has a crucial effect on the calculated difference between measured SVI and DSVI values, regardless of the MLSS concentration of the samples in the investigated wide range of $2.8-6.0 \mathrm{~kg} \cdot \mathrm{m}^{-3} \mathrm{MLSS}$. Although SVI measurement standards definitely prescribe the dilution of the samples in cases when the sludge volume is above $200-250 \mathrm{~cm}^{3} \cdot \mathrm{L}^{-1}$ in the graduated $1 \mathrm{~L}$ cylinder after $30 \mathrm{~min}$ of settling, according to the results presented, it is not recommended to dilute automatically. In case of a relatively low MLSS concentration applied in the bioreactor $\left(\approx 2.0-2.5 \mathrm{~kg} \cdot \mathrm{m}^{-3}\right.$ MLSS or less), even a 2-times dilution may shift the diluted MLSS concentration down to approx. $1 \mathrm{~kg} \cdot \mathrm{m}^{-3}$ MLSS in the measuring cylinder, which is about the lowest limit of good flocculation and therefore the settling test may lead to erroneous DSVI data. Designers are advised to be careful with data supplied as design parameters; the background and accuracy should be carefully controlled before calculations. 
Effect of BOD measuring method selection on $\mathrm{BOD}_{5}$ results

$\mathrm{BOD}_{5}$ concentration values of preclarified wastewater (i.e. wastewater sample taken after primary settling from the effluent of Sedipac 3D type compact primary clarifiers - incl. also grit and grease removal - at BCWWTP) measured by manometric method proved to be significantly higher than those obtained through electrochemical standard method, resulting in a difference of approx. 23\% for unfiltered and 15\% for filtered samples, on average. The results were statistically evaluated by ANOVA (analysis of variance) method, having chosen the measuring method (i.e. manometric vs. electrochemical) as fixed and sampling day as the random factor. At a significance level of 5\% the differences, effects and interactions proved to be significant, as shown in Fig. 7. Although the original electrochemical BOD measurement method does not contain stirring, in the second step the method was applied both with and without stirring to investigate the cause of the difference measured. Results suggested that continuous stirring can be the main factor responsible for the difference detected between the results of the two methods. While the electrochemical method does not apply stirring, bottles equipped for BOD measuring by manometer head should be completely and continuously stirred during the measurement. When both methods were applied with stirring, the difference measured proved to be non-significant at a significance level of 5\%. However, standard deviation of data from the electrochemical method was $2-4$ times higher compared to that of manometric values. These results also provide an explanation for the higher difference measured for unfiltered samples (23\%) compared to filtered ones (15\%). Thus, without stirring, suspended solids settled down to the bottom of measuring flasks resulting in remarkably poorer microbial availability of oxygen and substrates.

\section{Simulation results estimating denitrification efficiency using BOD based COD fractionation}

For simulation calculations the quality of influent wastewater entering the bioreactors was characterized for BCWWTP and BIAWWTP. The majority of WWTPs in Hungary face carbon deficiency or marginal availability of biodegradable organics (Tardy et al., 2012). At BCWWTP $\mathrm{BOD}_{5} / \mathrm{NH}_{4} \mathrm{~N}$ ratio of the typical inlet wastewater entering the biological step (i.e. preclarified wastewater) varied in the range of 4-6 which refers to moderate nitrogen removal ability. However, headworks and Sedipac 3D type lamella primary settlers keep the preclarified wastewater quality relatively balanced (compared to changes in the raw influent quality), and due to the mitigating effect of TSS removal by primary treatment, only moderate TSS, COD and $\mathrm{BOD}_{5}$ fluctuations may happen. At BIAWWTP the inlet wastewater entering the biological step (i.e. raw wastewater leaving the screens) had high ammonium content (typically in the range of $65-95 \mathrm{mg} \cdot \mathrm{L}^{-1} \mathrm{NH}_{4} \mathrm{~N}$ ). Since only screens represented the primary treatment prior to the biological step, huge variations could occur regarding the inlet $\mathrm{BOD}_{5} /$ $\mathrm{NH}_{4} \mathrm{~N}$ ratio (from 3.5 up to 10 ), resulting in appropriately poor or moderate, or even good or excellent, carbon availability for denitrification.

Results of simulation calculations presented in Fig. 8 show that the method applied for $\mathrm{BOD}_{5}$ analysis significantly affects the calculated denitrification efficiency through its strong influence on BOD-based COD fractionation for inlet wastewater entering the biological step. As highlighted in Fig. 8 b, the effects are significant, particularly in the case of marginal availability or severe deficiency of inlet organic carbon source. Modelling results shown in Fig. 8 proved that the best match between calculated and measured effluent concentrations of $\mathrm{N}$-forms could be provided by applying manometric inlet $\mathrm{BOD}_{5}$ concentrations for biodegradability-based COD fractionation. This fractionation is crucial for generating model input components. By applying BOD concentration measured by the electrochemical method, the slowly biodegradable COD fraction was underestimated, resulting in remarkably lower apparent denitrification efficiency.

In international wastewater laboratory practice the application of manometry is increasingly dominant due to its numerous advantages; however, most laboratories are accredited for and use both methods. Differences presented above may carry a latent risk for designers, particularly in the case of smaller or regional wastewater treatment plants where inlet $\mathrm{C} / \mathrm{N}$ ratio may typically not be favourable for denitrification due to the large catchment area, long sewer network and enormous load fluctuations.

\section{Recommendations and methods for appropriate BOD measurement practice}

The general use of the manometric method (HSI, 2004, No. MSZ E 21420-9:2004; APHA, 1999, No. 5210D) is unambiguously privileged in order to ensure accurate results with low standard
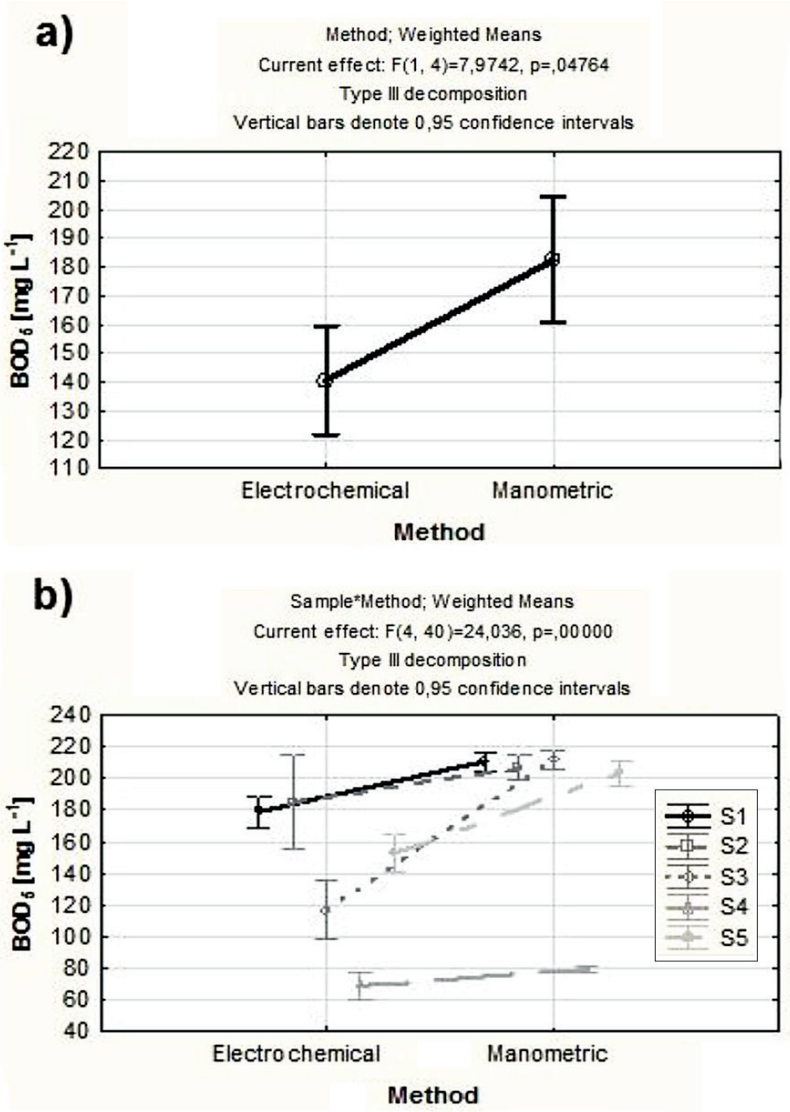

Figure 7. Results of ANOVA for unfiltered samples for a) method effect and $b$ ) sample - method interaction for 5 investigated samples $\left(S_{1-5}\right)$. ( $p_{\text {sample }}=0.026 ; p_{\text {sample }}^{* \text { method }} \approx 0 ; p_{\text {method }}=0.048$, in case when method effect was analysed as planned comparison: $p_{\text {method }} \approx 0$ ) 

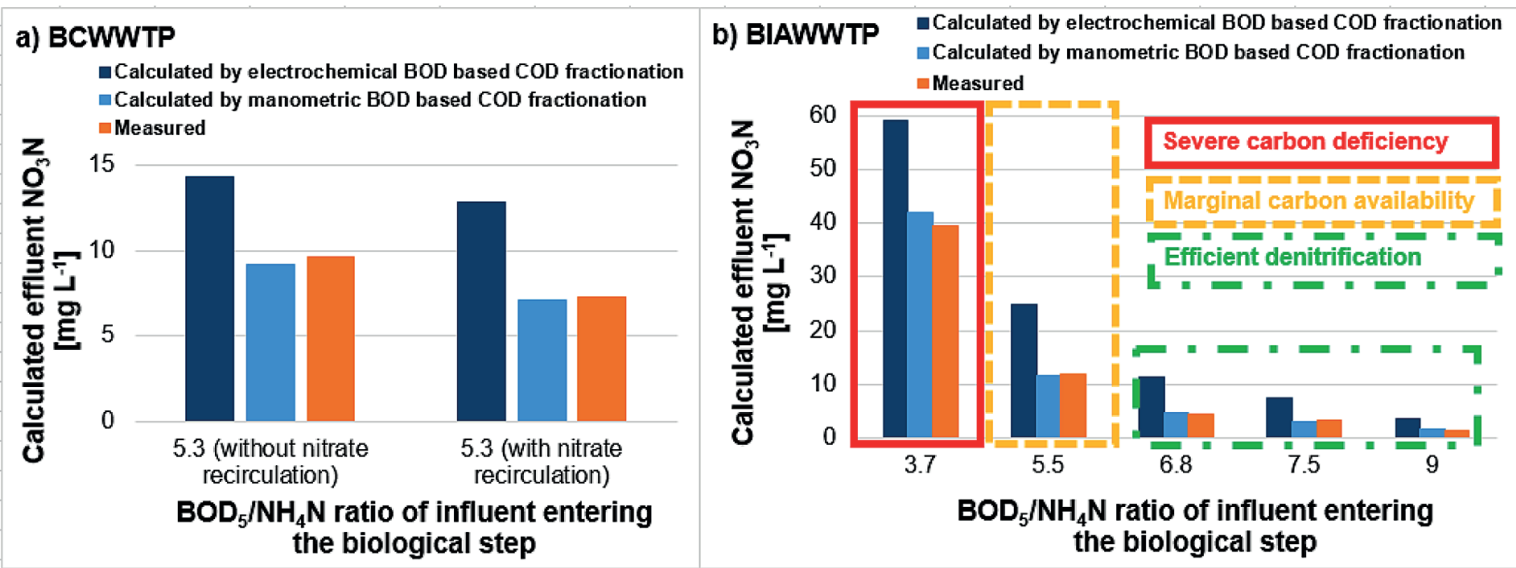

Figure 8. Impact of different $\mathrm{BOD}_{5}$ measuring methods on calculated denitrification performance as a function of inlet $\mathrm{C} / \mathrm{N}$ ratios (a) at BCWWTP for typical inlet wastewater quality with and without internal nitrate recirculation; (b) at BIAWWTP for the broad spectrum of possible inlet $\mathrm{C} / \mathrm{N}$ ratios. $\left(\mathrm{BOD}_{5} / \mathrm{NH}_{4} \mathrm{~N}\right.$ ratios indicated on the axis of the graphs refer to values calculated and expressed according to manometric $\mathrm{BOD}$.)

deviation and provide representative input parameter values for bio-kinetic models. Laboratories are advised to precisely indicate their applied measurement methods in datasupplying documents. If only electrochemically measured BOD concentrations are available, application of additional continuous stirring is recommended and more careful calculations may be needed, since BOD concentration might be underestimated. Supplementary simultaneous measurements of inlet BOD by both methods can be useful for corrective calculations, at least several times if possible.

\section{CONCLUSIONS}

This paper points out that carefully designed sampling and analysis as well as clear description of data origin and critical data evaluation are crucial for providing an appropriate basis for calculations leading to best technological solutions. Useful recommendations, as well as powerful and easily implemented methods have been presented which can be important for both designers and practitioners.

It has been illustrated that wastewater quality can significantly change in the sampling tubing and vessels; even nitrification may happen during the sampling processes.

The study highlighted that besides activated sludge floc structure, temperature and dilution, electron acceptor (i.e. DO and/or nitrate) availability as well as biochemical switch of the biomass investigated are also significant influencing factors having strong and synergistic effects on activated sludge settling results. These emphasized findings are recommended to be taken into special consideration in the case of sampling intermittently aerated bioreactors. For early indication of activated sludge floc structure transformations a combined, comparative method of using SVI and DSVI measurements simultaneously has been developed and successfully applied.

Significant differences have been found between $\mathrm{BOD}_{5}$ values of preclarified wastewater measured by electrochemical and manometric analysis methods, reaching $23 \%$, on average, for unfiltered and $15 \%$ for filtered samples, respectively. Simulation studies of Budapest Central and Biatorbágy WWTPs proved that the measured differences in $\mathrm{BOD}_{5}$ concentrations of influent entering the bioreactors remarkably affected the calculated denitrification efficiency, particularly in the case of low inlet $\mathrm{BOD}_{5} / \mathrm{NH}_{4} \mathrm{~N}$ ratio.
Recommendations elaborated for upgrading activated sludge settling and wastewater BOD measurements ensure higher transparency and comparability, as well as appropriate integration of wastewater and mixed liquor analysis methods into state-of-the-art design and operation practice in order to avoid modelling failures, and prevent expensive operation and costly corrections of misdesigned technologies.

\section{ACKNOWLEDGEMENTS}

The cooperation of Budapest Waterworks Pte. Ltd. facilitating on-site measurements, full-scale process modelling and supplying data is gratefully acknowledged, with special thanks to Csaba Haranghy, Bence Márialigeti, László Váci and Szabolcs Pintér. The valuable help of engineer colleagues at North Budapest WWTP (Budapest Sewage Works Pte. Ltd.) and János Csővári at Kecskemét WWTP (Bácsvíz Pte. Ltd.) is gratefully acknowledged. The helpful contribution of Dr Zsuzsanna Nagy (DHI Hungary Ltd.) enabled the access to WEST software for simulation calculations. Useful consultations with and technical support of Enrico Remigi (DHI Belgium) in modelling are also greatly appreciated. Authors are thankful to Prof. Sándor Kemény for his kind help in statistical evaluations. Authors express their special thanks to the laboratory and operational staff of the investigated wastewater treatment plants.

\section{REFERENCES}

\section{APHA (AMERICAN PUBLIC HEALTH ASSOCIATION) (1999)}

Standard Methods for the Examination of Water and Wastewater $\left(20^{\text {th }}\right.$ edn). Methods: No. 5210B., 5210C., 5210D. APHA, Washington DC.

ATV Design Standard A131 (2000) Dimensioning of single-staged activated sludge plants. ATV-DWA, Germany, Hennef.

DREWNOWSKI J and MAKINIA J (2014) The role of biodegradable particulate and colloidal organic compounds in biological nutrient removal activated sludge systems. Int. J. Environ. Sci. Technol. 11 (7) 1973-1988. https://doi.org/10.1007/s13762-013-0402-1

EKAMA GA, PITMAN AR, SMOLLEN M and MARAIS GVR (1984) Secondary settling tanks. Chapter 8. In: Theory, Design and Operation of Nutrient Removal Activated Sludge Processes. Water Research Commission, Pretoria. 8.1-8.14.

EKAMA GA, DOLD PL and MARAIS GVR (1986) Procedures for determining influent COD fractions and the maximum specific 
growth rate of heterotrophs in activated sludge systems. Water Sci. Technol. 18 91-114.

EKAMA GA, BARNARD JL, GÜNTHERT FW, KREBS P, MCCORQUODALE JA, PARKER DS and WAHLBERG EJ (1997) Secondary settling tanks: theory, modelling, design and operation. IAWQ Scientific and Technical Report No. 6. IAWQ, London. 41-65.

HAUDUC H, RIEGER L, OEHMEN A, VAN LOOSDRECHT MCM, COMEAU Y, HÉDUIT A, VANROLLHEGEM PA and GILLOT S (2013) Critical review of activated sludge modeling: state of process knowledge, modeling concepts, and limitations. Biotechnol. Bioeng 110 (1) 24-46. https://doi.org/10.1002/bit.24624

HENZE M, GRADY JR CPL, GUJER W, MARAIS GVR and MATSUO $\mathrm{T}$ (1987) A general model for single-sludge wastewater treatment systems. Water Res. 21 (5) 505-515. https://doi.org/10.1016/0043-13 54(87)90058-3

HSI (Hungarian Standards Institution) (2000) Standard methods for biochemical oxygen demand determination from water and wastewater - electrochemical method, No. MSZ EN 1899-1:2000; MSZ EN 1899-2:2000. Hungarian Standards Institution, Budapest.

HSI (Hungarian Standards Institution) (2004): Standard methods for biochemical oxygen demand determination from water and wastewater - manometric method, No. MSZ E 21420-9:2004. Hungarian Standards Institution, Budapest.

HSI (Hungarian Standards Institution) (2006): Standard methods for sludge volume index measurement, No. MSZ EN 14702-1,2:2006. Hungarian Standards Institution, Budapest.

JENKINS D, RICHARD MG and DAIGGER GT (2004) Manual on the Causes and Control of Activated Sludge Bulking, Foaming and other Solids Separation Problems. (3 $3^{\text {rd }}$ edn). CRC Press LCC, Boca Raton, Florida. 10, 23-24, 52-53.

JOBBÁGY A, SIMON J and PLÓSZ BGY (2000) The impact of oxygen penetration on the estimation of denitrification rates in anoxic processes. Water Res. 34 (9) 2606-2609. https://doi.org/10.1016/ S0043-1354(00)00013-0

LEE S-E, KOOPMAN B, BODE H and JENKINS D (1983) Evaluation of alternative sludge settleability indices. Water Res. 17 (10) 1421-1426. https://doi.org/10.1016/0043-1354(83)90273-7

OLSSON G, CARLSSON B, COMAS J, COPP J, GERNAEY KV, INGILDSEN P, JEPPSSON U, KIM C, RIEGER L,
RODRÍGEZ-RODA I and co-authors (2014) Instrumentation, control and automation in wastewater - from London 1973 to Narbonne 2013. Water Sci. Technol. 69 (7) 1373-1385. https://doi. org/10.2166/wst.2014.057

PLÓSZ BGY, JOBBÁGY A and GRADY JR CPL (2003) Factors influencing deterioration of denitrification by oxygen entering an anoxic reactor trough the surface. Water Res. 37 853-863. https://doi. org/10.1016/S0043-1354(02)00445-1

MAMAIS D, JENKINS D and PITT P (1993) RAPID COMMUNICATION: A rapid physical-chemical method for the determination of readily biodegradable soluble COD in municipal wastewater. Water Res. 27 (1) 195-197. https://doi.org/10.1016/00431354(93)90211-Y

RIEGER L, LANGERGRABER G, THOMANN H, FLEISCHMANN NG and SIEGRIST HR (2004) Spectral in-situ analysis of $\mathrm{NO}_{2}, \mathrm{NO}_{3}$, COD, DOC and TSS in the effluent of a WWTP. Water Sci. Technol. 50 (11) 143-152.

RIEGER L, LANGERGRABER G and SIEGRIST H. (2006)

Uncertainties of spectral in situ measurements in wastewater using different calibration approaches. Water Sci. Technol. 53 (12) 187-197. https://doi.org/10.2166/wst.2006.421

RIEGER L, TAKÁCS I, VILLEZ K, SIEGRIST H, LESSARD P, VANROLLEGHEM PA and COMEAU Y (2010) Data reconciliation for wastewater treatment plant simulation studies - planning for high-quality data and typical sources of errors. Water Environ. Res. 85 426-433. https://doi.org/10.2175/106143009X12529484815511

ROELEVELD PJ and VAN LOOSDRECHT MCM (2002) Experience with guidelines for wastewater characterization in The Netherlands. Water Sci. Technol. 45 (6) 77-87.

STOWA (1996) Methoden voor Inflientkarakterisierung - Inventarisatie en Richtlijnem. STOWA Report 80-96. STOWA, Utrecht.

TARDY GM, BAKOS V and JOBBÁGY A (2012) Conditions and technologies of biological wastewater treatment in Hungary. Water Sci. Technol. 65 (9) 1676-1683. https://doi.org/10.2166/wst.2012.062

WANNER J and JOBBÁGY A (2014) Activated sludge solids separations. Chapter 10. In: Jenkins D and Wanner J (eds.) Activated sludge - 100 Years and Counting. IWA Publishing, Glasgow. ISBN 9781780404936. 171-194. 